\title{
A Simple Model to Assess the Performance of an Overtopping Wave Energy Converter Embedded in a Port Breakwater
}

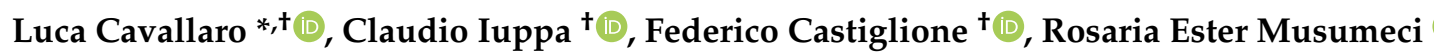 \\ and Enrico Foti \\ Department of Civil Engineering and Architecture, University of Catania, Via Santa Sofia, \\ 64-95123 Catania, Italy; ciuppa@dica.unict.it (C.I.); fredeck9617@gmail.com (F.C.); \\ rosaria.musumeci@unict.it (R.E.M.); enrico.foti@unict.it (E.F.) \\ * Correspondence: luca.cavallaro@unict.it \\ + These authors contributed equally to this work.
}

Received: 11 September 2020; Accepted: 28 October 2020; Published: 30 October 2020

\begin{abstract}
A numerical model for the optimization of the performance of an innovative overtopping breakwater for wave energy conversion is proposed. The model is based on the stochastic description of the overtopping phenomenon based on the results of extensive laboratory tests, and it is able to simulate the behavior of the device operating under any assigned sequence of sea states, thus allowing to easily obtain results that would otherwise require time consuming and costly physical model tests. The model is used here to identify the main geometrical parameters affecting the performance of the device and to optimize such parameters in order to maximize the average yearly output power. An application to a device embedded in the breakwater of Pantelleria Port (Sicily, Italy) is presented. The model is also proved to be useful to verify the possibility of further increasing the output power through the implementation of specific control strategies concerning the operation of the turbines. The work provides a better understanding of the influence that such a system could have on the energy system of small Mediterranean islands, for example in terms of contribution to the $\mathrm{CO}_{2}$ emission reduction.
\end{abstract}

Keywords: wave energy; OBREC; overtopping; turbine; SWAN

\section{Introduction}

Ocean tides and waves represent an exceptionally large and untapped source of energy which could be efficiently exploited, together with the most common renewable sources of energy (i.e., solar and wind power), to achieve a more sustainable world energy system (IEA-OES [1]).

Nowadays the installation and maintenance costs of the Wave Energy Converters (WECs) are high compared to other renewable sources of energy. In other to reduce these costs, WECs can be embedded in port breakwater and two main technologies of these devise exist: the Oscillating Water Column (OWC) and the Overtopping BReakwater for Energy Conversion (OBREC). The OWC technology is more mature the the OBREC technology, since a plant in a commercial phase already exist [2,3].

The present work concentrates on the Overtopping BReakwater for Energy Conversion (OBREC). Such a device has been designed to extract energy from the overtopping process which occurs at harbour rubble mound breakwaters. It consists of a concrete frontal ramp that reduces the friction of the breakwater and facilitates the overtopping of the waves into a reservoir located above sea level; then the water flows back to the sea through one or more low-head turbines [4-6].

The main advantage of such a device is that it can be totally embedded in a traditional rubble mound breakwater used for harbour protection from wave attack. This structural solution indeed 
favours a relevant reduction of the economic overload to implement WECs by carrying benefits such as [4]: (i) easier access to the device, which simplifies its construction, maintenance and connection to the electrical grid; (ii) similarity with traditional rubble mound breakwaters, which simplifies both design and construction activities; (iii) reduced sea waves intensity compared to offshore technologies, which diminishes the mechanical stress undergone by the device, as well as the amount of energy that can be extracted. In order to evaluate the performance of such a device several laboratory and numerical experiments were carried out [5-7].

The feasibility evaluation of investment in WEC construction requires a reliable assessment of the amount of energy that can be extracted by the device at a given location, as well as a procedure to predict how the variation of the parameters of the device will affect its productivity, in order to identify its optimal configuration. The performance assessment of the device and its optimization can be carried out by analyzing the results of physical model experiments or of time consuming detailed numerical simulation based, for example, on the solution of the Reynolds Averaged Navier-Stokes Equation $[8,9]$.

To overcome the cost and time limits of the above-mentioned methods, a numerical model based on a stochastic estimate of the overtopping discharges is proposed here. More specifically, the performances of the OBREC were recently analyzed through small-scale laboratory tests carried out at the Hydraulic Laboratory of the University of Catania. The measurement of the overtopping discharges were used to determine the probability distribution of the overtopping volumes for an OBREC device. The method is presented and discussed by Iuppa et al. [10] and it represents the basis for the implementation of the proposed numerical model able to simulate the behaviour of the OBREC operating under any assigned sequence of sea states.

In the present work, the model is applied to optimize a new device to be embedded in the breakwater of Pantelleria Port (Sicily, Italy). Such a case study has been chosen because it is representative of a typical situation of many small-islands in the Mediterranean Sea, or elsewhere, whose energetic independence coupled with the use of environmental-friendly technology may be very important to guarantee the life quality of the isolated coastal communities and fragile ecosystems. The model is used to evaluate the influence of the main geometrical parameters affecting the performance of the device and to verify the convenience of the implementation of turbine control strategies.

The paper is organized as follows: the following section describes the proposed model used to predict the overtopping volumes which enter the OBREC reservoir and to estimate the device output electrical power as a function of the geometry of the device and of the characteristics of the wave motion; the third section describes the case study and it illustrates the the numerical analysis carried out in order to estimate the wave characteristics in front of the breakwater of Pantelleria Port; the fourth section discusses the role of the geometrical parameters of the OBREC system to be optimized, with reference to the case study presented here; and the fifth section describes the optimization of the main geometrical parameters of the device. The last section contains some concluding remarks.

\section{Methodology to Estimate the Device Performance}

In order to estimate the performance of an OBREC device, whose main geometrical parameters are described in Figure 1, in the present paper the energy produced by the device was estimated through two steps. First, the time distribution of the individual overtopping volumes for each sea state was evaluated by applying the predictive method proposed by Iuppa et al. [10] validated on an extensive laboratory dataset. Such a methodology allows one to estimate the time distribution of the individual overtopping volumes once the characteristics of the incoming waves (i.e., significant wave height and mean wave period) and of the foreshore slope are known. Then, once the inflow discharges for each assigned sea state are generated, the behavior of the reservoir and the turbine is simulated, by considering mass conservation. 


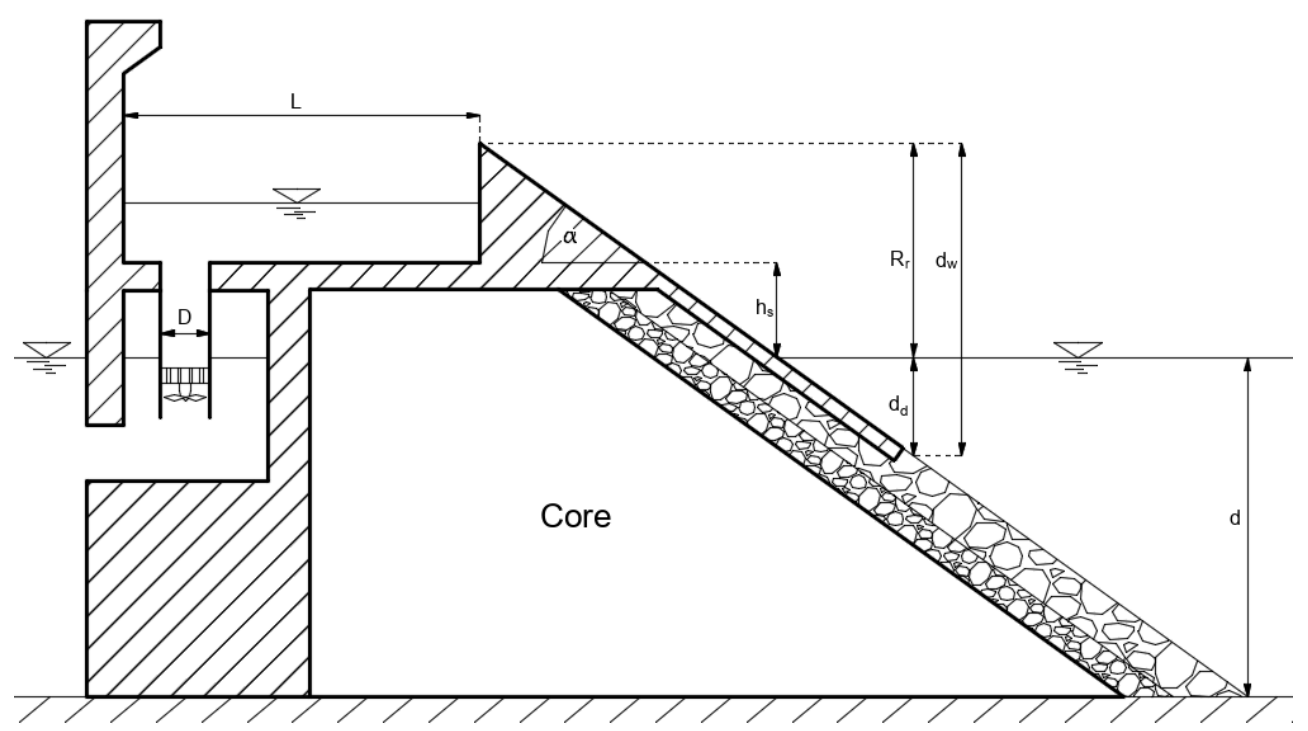

Figure 1. Sketch of an OBREC cross-section and definition of the main geometrical parameters to be considered for design.

Figure 2 shows the workflow of the proposed method. The first step is related to the generation of the overtopping discharge timeseries for a sea state. By using the method proposed by Iuppa et al. [10] and described in the Section 2.1, an overtopping volume distribution is evaluated for each geometric configuration of the device. Then by using such a distribution and a random probability generator, the timeseries of the overtopping discharge is obtained for each sea state. Then the outflow rate and the output power are evaluated, as described in Section 2.2, according to the reservoir and turbine characteristics.

(a)

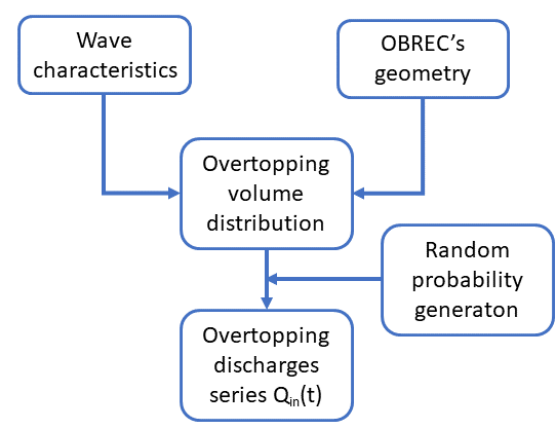

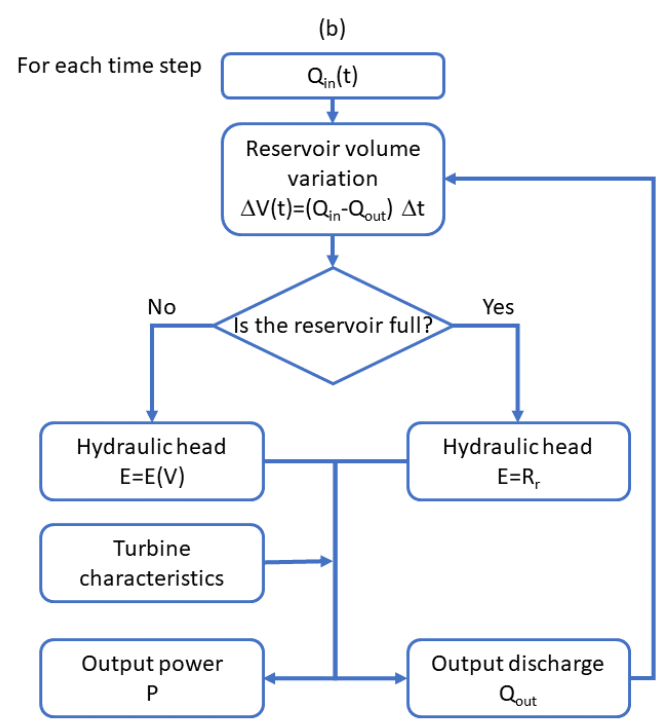

Figure 2. Workflow of the proposed method. (a) Overtopping discharge time series generation. (b) Output power $P$ evaluation.

\subsection{Time Distribution of the Individual Overtopping Volume}

As indicated in previous studies by van der Meer and Janssen [11], Franco et al. [12], Victor et al. [13], and confirmed by Iuppa et al. [10], the wave-by-wave overtopping volumes distribution fits well 
a two-parameter Weibull distribution function. As known, the two-parameter Weibull distribution function can be written as

$$
P_{V_{\text {in }}}(V)=P\left[V_{\text {in }} \geq V\right]=\exp \left(-\left(\frac{V}{a}\right)^{b}\right),
$$

where $P_{V_{\text {in }}}$ is the exceedance probability, $V_{i n}$ is the generic individual overtopping volume, $V$ is a reference value, $a$ is the scale factor and $b$ is the shape parameter. In order to evaluate the overtopping volume distribution, it is necessary to fix the exceedance probability and to estimate the parameters $a$ and $b$ of the Weibull distribution.

As regards the parameter $a$, it can be estimated through the following relationship:

$$
a=\frac{1}{\Gamma\left(1+\frac{1}{b}\right)} \times \frac{q_{i n} N_{w} T_{m}}{N_{o w}}=\frac{1}{\Gamma\left(1+\frac{1}{b}\right)} \times \frac{q_{i n} T_{m}}{P_{o w}},
$$

where $\Gamma$ is the gamma function, $q_{i n}$ is the average overtopping discharges, $N_{o w}$ is the number of overtopping waves, $N_{w}$ is the total numbers of incident waves and $T_{m}$ is the mean wave period. The ratio between $N_{o w}$ and $N_{w}$ is the probability of overtopping $P_{o w}=\frac{N_{o w}}{N_{w}}$.

Based on comparisons between the data obtained from an experimental campaign with literature prediction methods, newer methods were proposed by Iuppa et al. [10] to estimate the variables of Equation (2). A brief description of these methods is given below, while the interested reader is referred to the work of Iuppa et al. [10] for more details.

The average overtopping discharges $\left(q_{\text {in }}\right)$ is defined as

$$
q_{i n}=\gamma_{V} \times c_{1} \times \exp \left[-\left(c_{2} \times \frac{R_{r}^{*}}{\gamma_{f} \gamma_{\beta}}\right)^{c_{3}}\right] \times \sqrt{g \times H_{m 0}^{3}}
$$

where $R_{r}^{*}=R_{r} / H_{m 0}$ is the relative crest free-board of front reservoir, $R_{r}$ is the crest free-board of front reservoir, $H_{m 0}$ is the incident significant wave height in the frequency domain at the toe of the structure, the coefficients $c_{1}$ and $c_{2}$ are obtained by Equations (4) and (5) [14]

$$
\begin{aligned}
& c_{1}= \begin{cases}0.09-0.01 \times(2-\cot \alpha)^{2.1} & \text { for } \cot \alpha \leq 2 \\
0.09 & \text { for } \cot \alpha>2\end{cases} \\
& c_{2}=\left\{\begin{array}{lll}
1.50+0.42 \times(2-\cot \alpha)^{1.5} & \text { for } \cot \alpha \leq 2 \\
1.50 & \text { for } \cot \alpha>2 \\
, & &
\end{array}\right.
\end{aligned}
$$

with a maximum value of 2.35 for $c_{2}$, while the coefficient $c_{3}$ is equal to 1.3 , and $\alpha$ is the slope angle of the structure. The coefficients $\gamma_{V}, \gamma_{f}$ can be predicted as

$$
\begin{aligned}
& \gamma_{V}= \begin{cases}0.378 \times R_{r}^{* 2}-0.88 \times R_{r}^{*}+1.65 & \text { if } R_{r}^{*} \geq 0.8 \\
1 & \text { if } R_{r}^{*}<0.8\end{cases} \\
& \gamma_{f}= \begin{cases}\tanh \left(7.47 \times\left(\frac{d_{d}}{L_{m-1,0}}\right)^{0.42}\right) & \text { if } \frac{d_{d}}{L_{m-1,0}} \geq 0.006 \\
0.7 & \text { if } \frac{d_{d}}{L_{m-1,0}}<0.006\end{cases}
\end{aligned}
$$


while the coefficient $\gamma_{\beta}$ can be predicted using the relationship suggested by the EurOtop Manual [15]

$$
\gamma_{\beta}=\left\{\begin{array}{llr}
1-0.0063 \times|\beta| & \text { if } & 0^{\circ} \leq|\beta| \leq 80^{\circ} \\
0.736 & \text { if } & 80^{\circ}<|\beta| \leq 110^{\circ} \\
& &
\end{array}\right.
$$

with $\beta$ the angle between the direction of the waves and the perpendicular to the long axis of the dike. For $|\beta|>110^{\circ}$ the average overtopping discharge is assumed to be null.

The probability of overtopping $\left(P_{\text {ow }}\right)$ is defined as

$$
P_{\text {ow }}=\exp \left[-\left(c \times R_{r}^{*}\right)^{2}\right],
$$

where the parameter $c$ can be evaluated by using the relationship

$$
c=\frac{1}{0.36 \times d_{w}^{*}+0.92}
$$

where $d_{w}^{*}=d_{w} /\left(R_{r}+d t\right)$ is the dimensionless vertical height of sloping plate, $d_{w}$ is the vertical height of sloping plate and $d$ is the water depth at the structure toe.

The shape coefficient $b$ can be estimated by adopting the methodology proposed by Victor et al. [13] and a correction coefficient $C_{b}$ :

$$
\left.b=C_{b}\left[\exp \left(-2.0 \times R_{r}^{*}\right)+(0.56+0.15 \times \cot \alpha)\right)\right]
$$

$C_{b}$ allows us to take into account the effect of the vertical length of the submerged ramp of the device and it is defined as

$$
C_{b}=\left(1.16-0.15 \times d_{w}^{*}\right)
$$

The individual overtopping volume duration can be evaluated using the relationship

$$
\frac{T_{V}}{T_{m}}=C_{t 1} \times\left(\frac{V_{i n}}{V_{m}}\right)^{C_{t 2}}
$$

where $T_{m}$ is the mean wave period, $V_{m}$ is the average wave overtopping volume, $C_{t 1}$ and $C_{t 2}$ can be estimated by using the relationships

$$
\begin{gathered}
C_{t 1}=0.30 \times R_{r}^{*-0.193} \\
C_{t 2}=\max \left[0.5-0.4 \times R_{r}^{*}, 0.1\right] .
\end{gathered}
$$

The above equations were calibrated on a structure characterized by a seaside slope equal to 2:3 and with the following range of the input parameters: $0.4<R_{r}^{*}<2.0,0<\frac{d_{d}}{L_{m-1,0}}<0.290$, and $0.2<d_{w}^{*}<1$.

\subsection{Hydraulic Model of the OBREC System}

Once the inflow discharges for each assigned sea state are generated, the initial condition of the reservoir is set as empty, and a numerical integration of the continuity equation is carried out. The water volume variation inside the reservoir during a time interval of $d t$ is evaluated as:

$$
\Delta V_{r}(t+d t)=Q_{\text {in }}(t+d t)-Q_{\text {out }}(t),
$$

where $V_{r}$ is the water volume inside the reservoir at the generic time $t, Q_{i n}$ is the inflow rate and $Q_{\text {out }}$ is the outflow rate. If the new volume exceeds the physical volume of the reservoir, the new volume is set equal to such an upper limit. The hydraulic head on the turbines $(E)$ is calculated differently 
whether the volume of water inside the reservoir is greater or lower than the volume of the pipes above the s.w.l. $\left(V_{\text {pipe }}\right)$ :

$$
E=\left\{\begin{array}{lll}
\frac{V_{r}(t+d t)}{N \times A_{p i p e}} & \text { for } \quad V_{r}(t+d t) \leq V_{\text {pipe }} \\
\frac{V_{r}(t+d t)-V_{\text {pipe }}}{L \times l_{r}}+\frac{V_{\text {pipe }}}{N \times A_{\text {pipe }}} & \text { for } \quad V_{r}(t+d t)>V_{\text {pipe }} \\
\hline & &
\end{array}\right.
$$

where $N$ is the number of pipes, $A_{\text {pipe }}$ is the pipe cross section area, $L$ is the cross-shore width of the reservoir and $l_{r}$ is the longitudinal length of the reservoir. The outflow rate and the output power $(P)$ of the turbines are evaluated according to the performance curve of the turbine. The evaluated outflow rate can be used in Equation (16) to determine the new variation of the volume of water inside the reservoir, and hence all the quantities related to the next time interval.

\section{Optimization of an OBREC at the Pantelleria Harbor}

In the present work an application of the proposed method to the design of an OBREC system to be installed at the Harbor of Pantelleria is discussed, in order to show how the section of the OBREC system can be optimized at a specific site, based on the known wave climate. In this way, it is also possible to highlight what are the most important geometrical parameters that control the energy production of the device. In the following, first a description of the case study is given, then the nearshore wave climate at the site is derived from offshore data through the application of the SWAN wave propagation model.

\subsection{Site Description}

Pantelleria is a small Italian island $\left(83 \mathrm{~km}^{2}\right)$ located $110 \mathrm{~km}$ South-West of Sicily (Figure 3), in the Strait of Sicily, with a resident population of about 7700 inhabitants which is further increased by tourists in the period from May to September. The yearly energy consumption of the island is about $79,000 \mathrm{MWh}$, of which almost $50 \%$ is electricity (the remaining part is either gasoline or diesel for transport purposes, or GPL for heating and cooking purposes). Due to the island being isolated from continental Italy, the largest portion of the electricity (about 44,000 MWh per year) is locally produced by means of a diesel thermoelectric plant, whereas a very small renewable part is produced via solar panels (less than 200 MWh per year) (PAES [16]). The port of Pantelleria is located in the North-West side of the island. The port is protected by rubble-mound breakwater oriented in a NE direction, with a $40 \mathrm{t}$ concrete block 2:1 slope armour layer. The water depth at the head of the main breakwater is about $12 \mathrm{~m}$. 

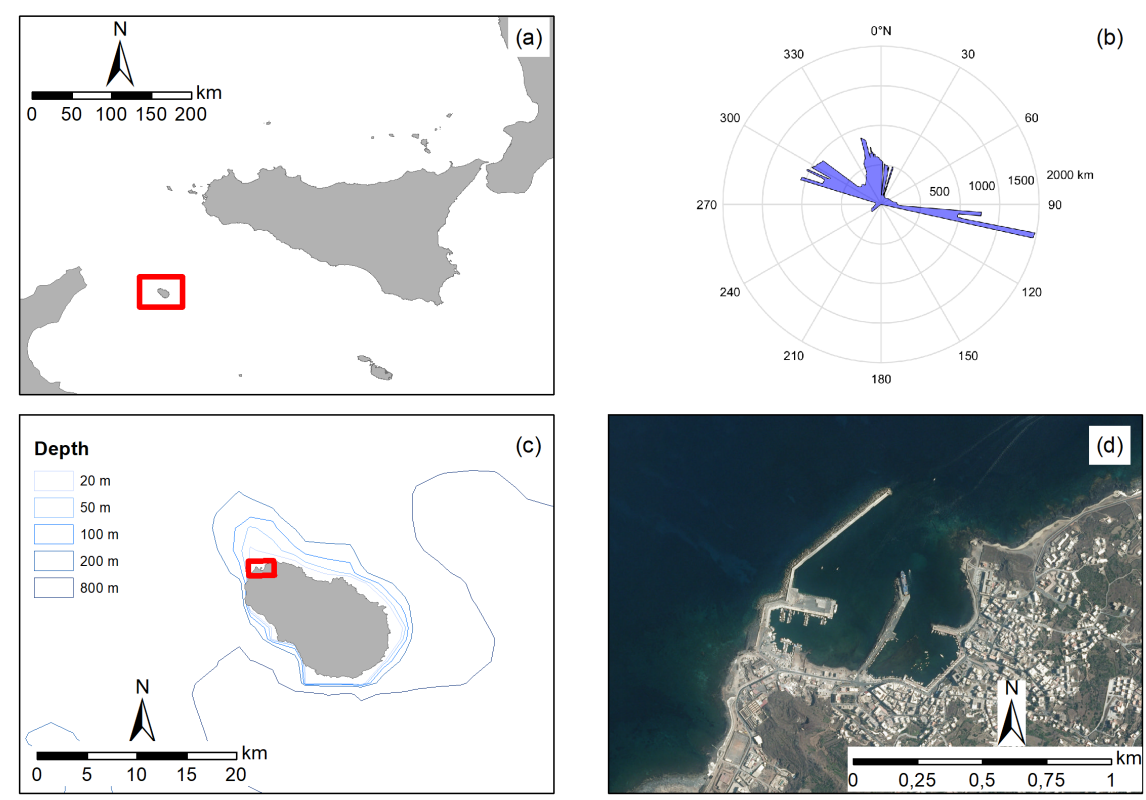

Figure 3. (a) Location of Pantelleria Island (Sicily, Italy). (b) Geografic fetch. (c) Location of the Port of Pantelleria. (d) Layout of the Port of Pantelleria.

\subsection{Nearshore Wave Climate at the Site of Interest}

The wave climate in the study area was evaluated through the numerical model Simulating WAves Nearshore (SWAN) [17]. The model can estimate the variations of the action density in space and time taking into account the processes of wind generation, white-capping, bottom friction, and quadruplet wave-wave interactions. SWAN was ran in third-generation mode and neglecting the effects of the depth-induced wave breaking and of the triad wave interactions because the present analyses are mainly focused on depths greater than or equal to $10 \mathrm{~m} \mathrm{[18].}$

Two data sources were used to reconstruct the morphology of the seabed-the data obtained from the charts of the Italian Navy Hydrographic Institute (NHI) and that from the archive of the European Marine Observation and Data Network (EMODnet).

The wave data were provided by Copernicus Marine Environment Monitoring Service (CMEMS) which represents one component of Copernicus services (land monitoring, emergency management, marine monitoring, atmosphere monitoring, security and climate change). Such a data set covers the period from February 2006 to January 2018 (about 12 years) and is composed by hourly wave parameters at $1 / 24^{\circ}$ horizontal resolution covering the Mediterranean Sea and extending up to 18.125 W into the Atlantic Ocean.

The bathymetric data was interpolated on an unstructured grid discretized with 9218 nodes and 17661 triangular elements. The grid resolution was assumed constant for depths shallower than $50 \mathrm{~m}$ and deeper than $500 \mathrm{~m}$, while it varies linearly in range the 50-500 m. Accordingly, the mesh sizes are $100 \mathrm{~m}$ for depths shallower than 50 , and $400 \mathrm{~m}$ for depths deeper than $500 \mathrm{~m}$, and varies linearly between 100 and $400 \mathrm{~m}$ for depths in the range between 50 and $500 \mathrm{~m}$. The sea side boundary was defined in order to coincide with the polyline passing through 22 points of the Copernicus grid data. The data of such points were used to define the wave characteristics at the sea side boundary, where a JONSWAP spectrum was assumed. The spectrum was discretized into 36 directions and 50 frequencies in a range of $0.04-0.8 \mathrm{~Hz}$, which corresponds to range of 1.25-25 s in terms of time.

Figure 4 shows the computational domain and the bathymetric map used for the numerical simulation. 


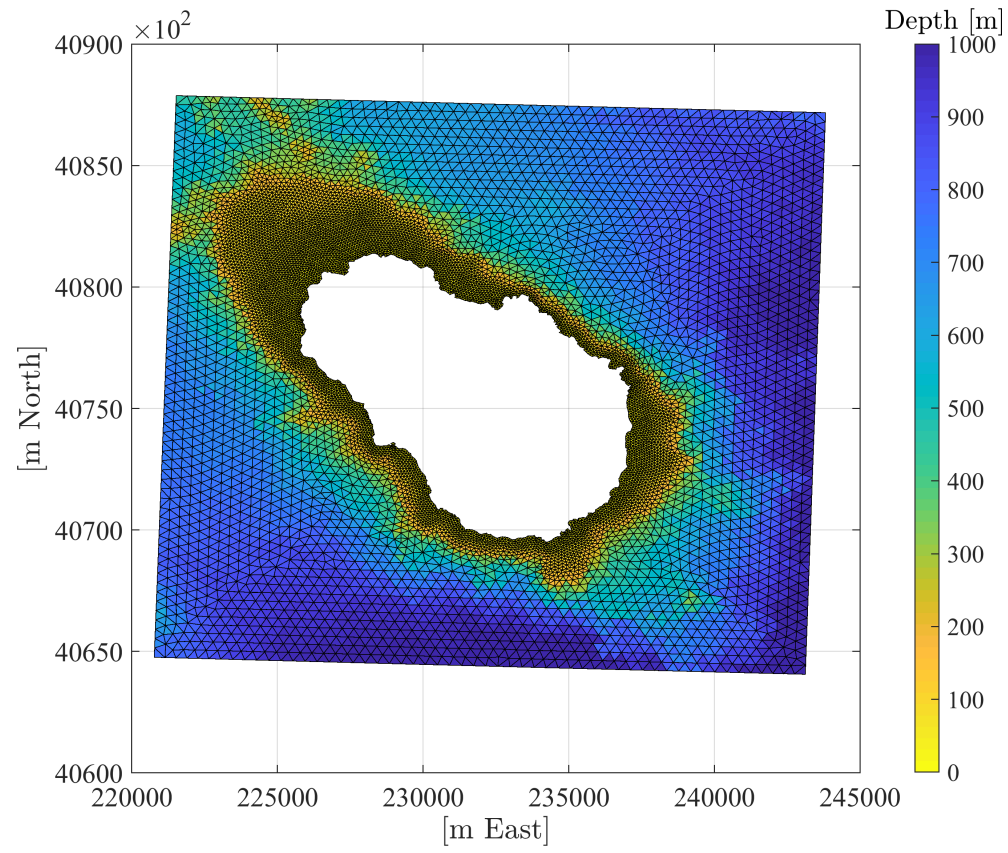

Figure 4. Computational domain and bathymetric map used for the numerical simulation.

The wave energy assessment was carried out by means of the components of the energy transport estimated by SWAN:

$$
\begin{aligned}
& P_{x}=\rho g \int_{0}^{2 \pi} \int_{0}^{\infty} c_{x} \times E(\sigma, \theta) d \sigma d \theta \\
& P_{y}=\rho g \int_{0}^{2 \pi} \int_{0}^{\infty} c_{y} \times E(\sigma, \theta) d \sigma d \theta .
\end{aligned}
$$

The average wave energy flux per unit crest length is shown in Figure 5.

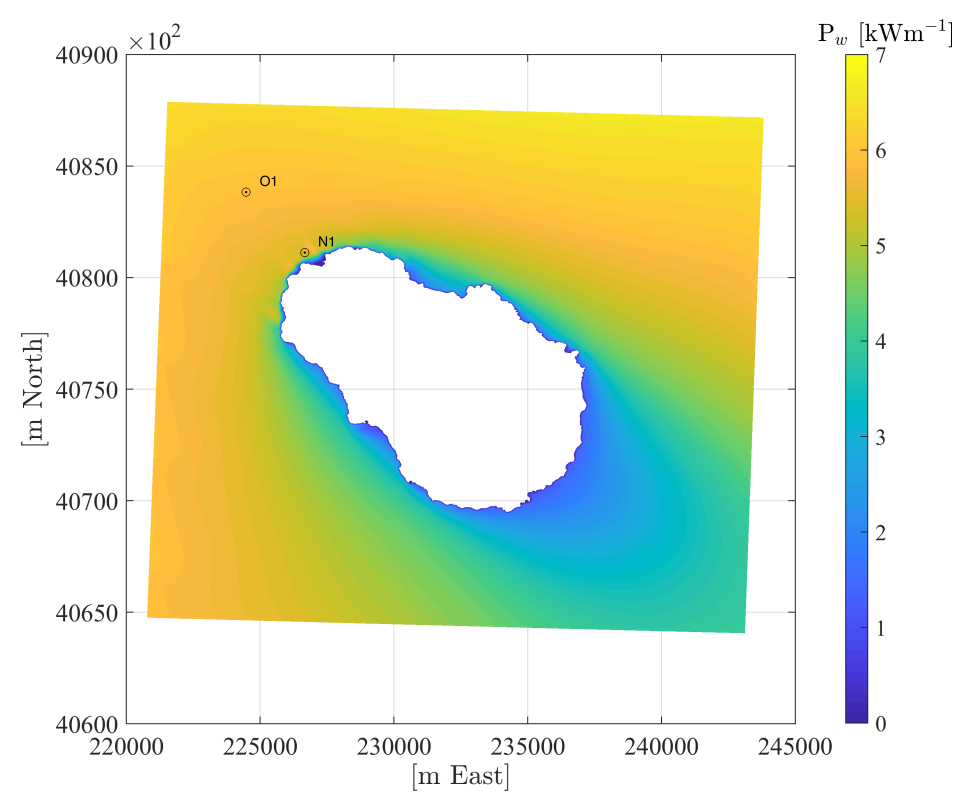

Figure 5. Average wave energy flux per unit crest length around the island of Pantelleria between 2013 and 2017 (five years). For the Pantelleria port, the points O1 and N1 are representative of offshore and nearshore wave climate. 
The spatial wave energy distribution around the island is almost constant. The offshore average wave energy flux is in the range $5.5-7 \mathrm{kWm}^{-1}$. Such values are consistent with the values estimated by Reference [19]. Along the South-East side, a decrease in wave energy is observed. In this zone the wave energy flux is in the range $3-4 \mathrm{kWm}^{-1}$. Such a spatial energy distribution is caused by the fact that the most energetic storms come from the western Mediterranean basin. Such storms are generated by the intense winds blowing from North-West (i.e., Mistral and Tramontane) and the long fetches that start from the Gulf of Lion. About this, Reference [20,21] estimated that the zone located between the Balearic Islands and the western coast of Sardinia is characterized by an average wave power flux above $12 \mathrm{kWm}^{-1}$.

For the study area, Figure 6 shows the offshore and the nearshore wave energy distribution with respect to the energy period $\left(T_{e}\right)$ and the significant wave height $\left(H_{m 0}\right)$. The coordinates of the offshore (O1) and the nearshore (N1) points are 224,476 m E-4,083,826 m N and 226,666 m E$4,081,121 \mathrm{~m} \mathrm{~N}$, respectively.
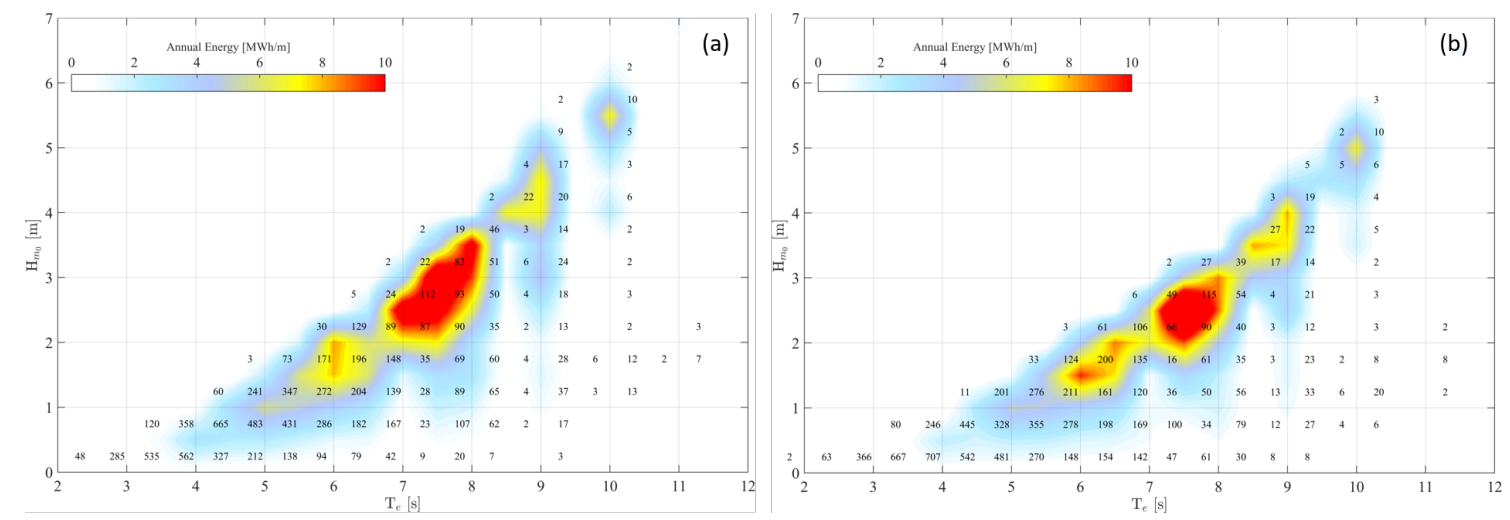

Figure 6. Average wave energy per unit crest length: (a) point O1; (b) point N1. The color scale represents annual energy per meter of wave front (in $\mathrm{MWhm}^{-1}$ ). The numbers within the graph indicate the occurrence of sea states (in number of hours per year).

Figure 7 shows the wave power climate for the two selected sites. At site $O 1$, the wave energy is concentrated in the classes over a range of $6-9 \mathrm{~s}$ with respect to $T_{e}$ and between 2 and $4 \mathrm{~m}$ with respect to $H_{m 0}$, with an annual frequency of $11 \%$. The percentage of "no calm", that is, waves with a significant wave height greater than $0.5 \mathrm{~m}$, is approximately $73 \%$. Waves with higher energy content come from the sector at $300-330^{\circ} \mathrm{N}$ with a frequency of $34 \%$. At site $N 1$, the wave energy is concentrated in the classes over a range of $6-9 \mathrm{~s}$ with respect to the $T_{e}$ and between 2 and $3.5 \mathrm{~m}$ with respect to $H_{m 0}$, with an annual frequency of $8 \%$. The percentage of "no calm" is approximately $58 \%$. Waves with higher energy content come from the sector at $310-330^{\circ} \mathrm{N}$ with a frequency of $37 \%$.

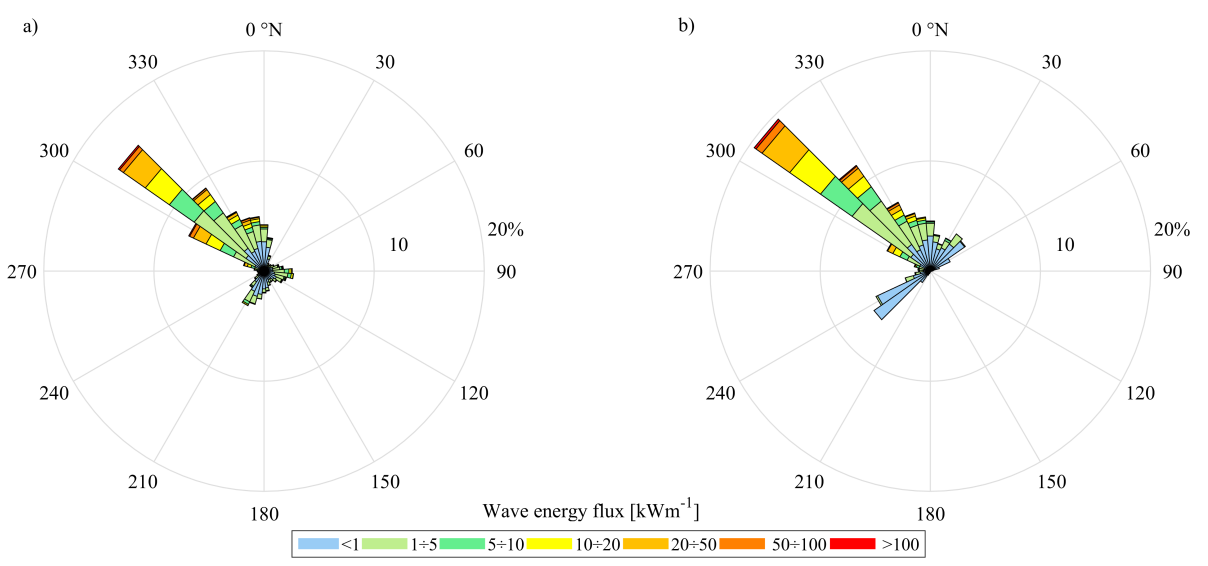

Figure 7. Directional wave energy flux distribution at the points O1 (a) and N1 (b). 


\section{Geometrical Parameters of the OBREC to Be Optimized}

The optimization of the geometrical configuration of the OBREC device to maximize the electrical power production is carried out by analyzing the influence of the following four geometrical parameters: crest free-board of the front reservoir $\left(R_{r}\right)$; height of the bottom of the reservoir on the s.w.l. $\left(h_{s}\right)$; length of the submerged ramp $\left(d_{d}\right)$; number of turbines installed $(N)$. These parameters are described in the sketch of an OBREC's cross-section in Figure 1.

Due to the complexity of the several process involved in the OBREC, it is no possible to find dimensionless parameters which could represent the whole problem. Therefore, the optimization process was carried out by adopting dimensional quantities.

The crest free-board of the front reservoir represents the main obstacle to the overtopping of the waves. The increase of $R_{r}$ compared to the incident wave height causes a reduction both of the non-dimensional mean overtopping discharge and of the probability of overtopping. However, the value of $R_{r}$ corresponds to the maximum turbine hydraulic head, thus implying that an increase of such a value could allow the extraction of enough energy to compensate the decrease due to the lost volumes of water.

The overtopping volume into the reservoir starts accumulating at the height of the bottom of the reservoir, thus implying that an increase in $h_{s}$ causes an increase of the mean hydraulic turbine head $(E)$. However, for a given value of $R_{r}$, the increase of the height of the bottom of the reservoir with respect to the mean sea water level produces also a reduction of its maximum volume and consequently the increase of the probability of rejecting part of the overtopping volumes due to the already reached maximum capacity.

The submerged ramp is included in the device with the purpose of lowering the friction of the breakwater, and it is therefore expected that its extension positively affects the energy production. However, the cost of the structure increases as the lenght of the smooth impermeable ramp increases. At the same time, the wave overtopping which reaches the rear side of the breakwater increases as the ramp length increases [5].

The number of turbines (and related exhaust pipes) installed affects the value of the outflow rate. A greater number of turbines implies a faster emptying of the reservoir, thus reducing both the mean hydraulic head and the probability of rejecting part of the overtopping volumes.

Three further geometrical parameters which could be relevant in evaluating the output power of the OBREC are the cross-shore width of the reservoir $(L)$, the angle of the foreshore slope $(\alpha)$ and the longitudinal width of the OBREC $(l) . \alpha$ can affect the wave overtopping discharge while $L$ and $l$ can affect the head on the turbine and the total volume which pass through the turbine. As regards the cross-shore width of the reservoir and the slope angle, they were defined according to the exiting characteristics of the breakwater of Pantelleria port and some environmental constraint, that is, the presence of protected Posidonia Oceanica meadow in front of the breakwater. In particular, the analysis was carried out considering $L=5 \mathrm{~m}$ and $\alpha=34^{\circ}$. The longitudinal length of the OBREC, that is the length of the breakwater where the OBREC is installed, does not affect the performances of the device if the wave climate is approximately constant within such a length, hence the parameter is not relevant for the proper dimensioning of the device. In the present analysis a longitudinal length $l$ equal to $260 \mathrm{~m}$ has been adopted, which is the length of the new extension of the breakwater.

The present analysis was performed assuming the use of the Kaplan turbines ZD760-LM-80 produced by the Electway Electric. Such turbines have a diameter equal to $80 \mathrm{~cm}$ and an operative head in the range $2-6 \mathrm{~m}$.

\section{Results}

The main results of the model concerning the four investigated parameters (namely the crest freeboard of the front reservoir, $R_{r}$, the height of the bottom of the reservoir, $h_{s}$, the length of the submerged ramp, $d_{d}$, and the number of installed turbines $N$ ) are presented and discussed in the following paragraphs. The range of the analysed parameters were chosen according to the wave 
climate in front of the Port of Pantelleria and to the characteristics available turbines. The results were obtained by considering the wave data in the period 2013-2017. The Copernicus data base provides with data from 2006 to 2018 but thanks to stationary of the average wave height at the site, the analyses were limited to a period of 5 years in order to limit the computational time.

\subsection{Effects of $R_{r}$ and $h_{s}$}

The crest free-board of the front reservoir and the height of the bottom of the reservoir are analyzed together since they are directly related to the capacity of the reservoir itself.

Figure 8 shows the results given by the numerical model applied to an OBREC as a function of $h_{s}$ and $R_{r}$. The simulations consider a length of the submerged ramp of $1 \mathrm{~m}$ and a number of turbines equal to $50 . h_{s}$ ranges between $1.9 \mathrm{~m}$ and $2.5 \mathrm{~m}$, and $R_{r}$ ranges between $2.25 \mathrm{~m}$ and $3.75 \mathrm{~m}$. Figure $8 \mathrm{a}$ shows the yearly average output power of the OBREC $P_{m}$, obtained by considering the frequency distribution of significant wave height at point N1. Figure $8 b$ shows the yearly average outflow rate of the OBREC $Q_{m}$. Such a parameter represents the average ratio between the total volume effectively collected yearly by the reservoir and the time during which it has been collected, thus it is not equal to the average overtopping inflow rate since part of the overtopped volumes can be rejected. Figure $8 \mathrm{c}$ shows the average hydraulic head $E_{m}$. This parameter, in contrast to $Q_{m}$, is not averaged over the entire functioning period of the device, but over the period during which there is water inside the reservoir of the OBREC, and it can hence increase even if $P_{m}$ decreases (because the time of functioning of the device changes with $R_{r}$ and $h_{s}$ ). Figure $8 \mathrm{~d}$ shows the percentage of time when the reservoir is full $\left(t_{p}\right)$. Such a parameter is obtained as the ratio between period during which the reservoir of the OBREC is full because the maximum volume is already reached and the overall time of functioning of the device during the observation period.
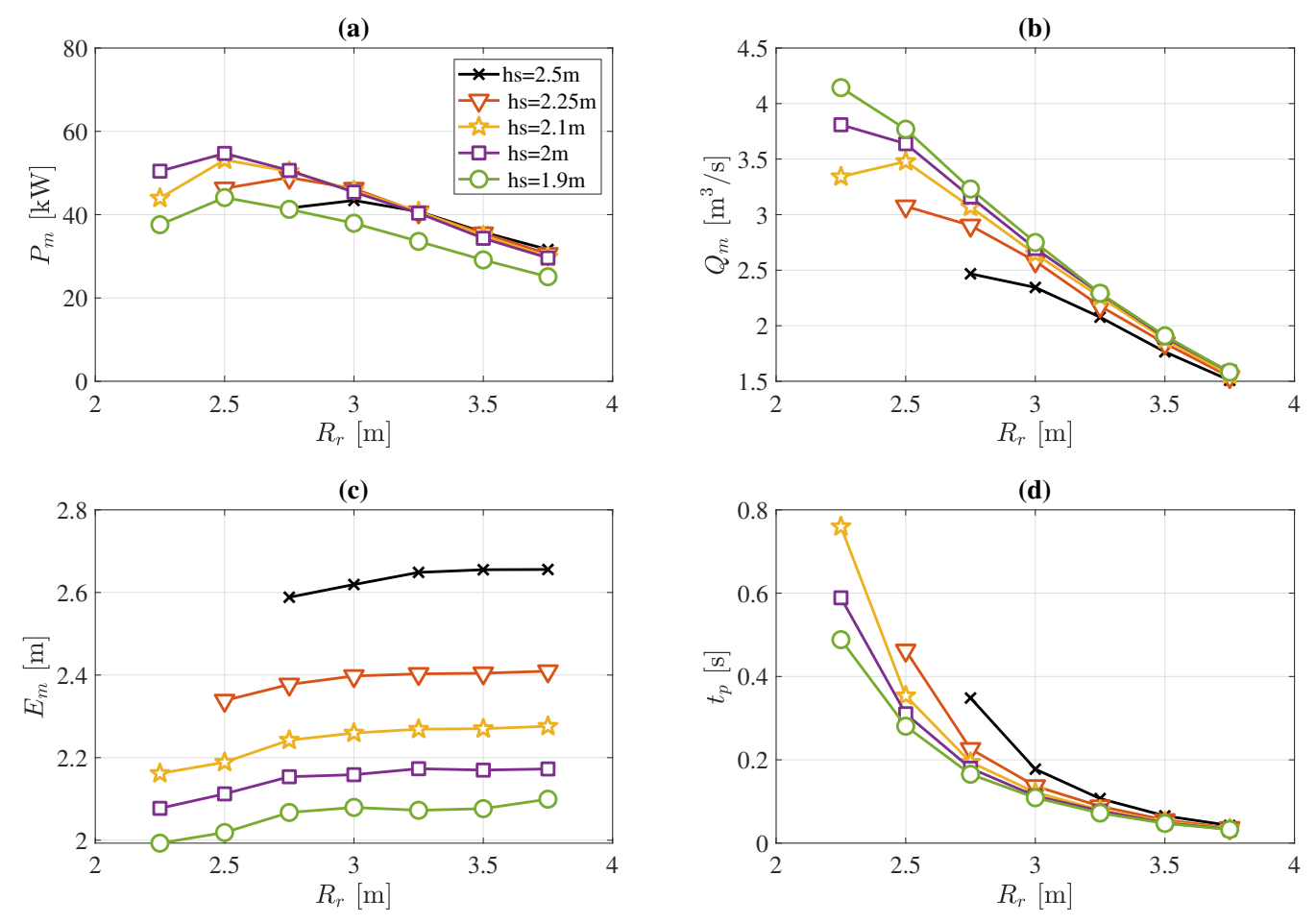

Figure 8. Effects of $R_{r}$ and $h_{s}\left(N=50\right.$ and $\left.d_{d}=1 \mathrm{~m}\right)$ during the period 2013-2017 on the: (a) yearly average output power; (b) yearly average outflow rate; (c) average hydraulic head; (d) percentage of time when the reservoir is full.

Figure 8a shows that, for a given $h_{s}$, the average power initially increases with $R_{r}$ up to a maximum. This result is mainly due to the increase in the volume of the reservoir and the consequent reduction of 
rejected volumes, as confirmed by the decreasing values of $t_{p}$ (Figure $8 \mathrm{~d}$ ) and by the relatively small slope of the $Q_{m}$ curves (Figure $8 \mathrm{~b}$ ).

A further increment in $R_{r}$ causes a decrease of the output power due to the decreasing values of $Q_{m}$ (Figure $8 \mathbf{b}$ ) which are not balanced by the small increase of the average hydraulic head (Figure 8c). Consequently, the variation in capacity of the reservoir become less and less relevant, as it can be noticed by significantly different gradients of the curves in Figure $8 \mathrm{~b}, \mathrm{~d}$.

Figure 8a,b show that $P_{m}$ and $Q_{m}$ have a different trend for low values of $R_{r}$. More in details, as already indicated, $P_{m}$ has a maximum while $Q_{m}$ shows a generally decreasing trend as $R_{r}$ increases. Such a difference is due to the minimum operative head of the adopted turbines, which is equal to $2 \mathrm{~m}$. Therefore, for head lower than $2 \mathrm{~m}, Q_{m}$ is greater than zero but $P_{m}$ is null.

As regards the effect of the variation of $h_{s}$, it can be noticed that for high values of $R_{r}$ (that is when the capacity of the reservoir does not affect the performance of the device) it is convenient to adopt a configuration with larger values of $h_{s}$ since this allows the average hydraulic head to rise (Figure 8c) with a minimal reduction of the collected volumes (Figure 8b). For small values of $R_{r}$ (that is when the low capacity of the reservoir considerably affects the performances of the device) it is better to reduce $h_{s}$ (and therefore $E_{m}$ ) in order to reduce the amount of lost overtopping volume. A device with $h_{s}$ lower than the minimum hydraulic head required by the turbine (i.e., $2 \mathrm{~m}$ ) should not be used, because the volume collected in the lower part of the reservoir is discharged without producing any power.

For the analysed site, the optimal configuration of the above described parameter is obtained for $h_{s}=2 \mathrm{~m}$ and $R_{r}=2.5 \mathrm{~m}$, with a corresponding value of $P_{m}=54.7 \mathrm{~kW}$.

Additional analyses, not reported here for the sake of brevity, indicate that such an optimal configuration is not affected by the variation of the length of the submerged ramp and of the number of installed turbines, which influences just the total value of the extracted energy.

\subsection{Effects of $d_{d}$}

The effect of the length of the submerged ramp, which is the portion of the traditional rubble mound replaced with a low-friction smooth concrete ramp, has been analysed in terms of the yearly average output power $P_{m}$ considering the OBREC configuration with the optimal values of $R_{r}$ and $h_{s}$ and with 50 turbines installed along the breakwater. The results concerning the yearly average output power are shown in Figure 9.

For values of $d_{d}$ smaller than $2 \mathrm{~m}$, an increase of $d_{d}$ strongly influences the performance of the device, due to the friction reduction of the armour layer. Indeed, for $d_{d}=1 \mathrm{~m}$ the average output power increases more than $20 \mathrm{~kW}$ with respect to the case $d_{d}=0 \mathrm{~m}$. For larger values of $d_{d}$, the increase of the ramp length is not as much effective in terms of output power. Moreover, this could also cause excessive structural stress for the ramp itself due to the increased moment created by the pressure acting under the ramp.

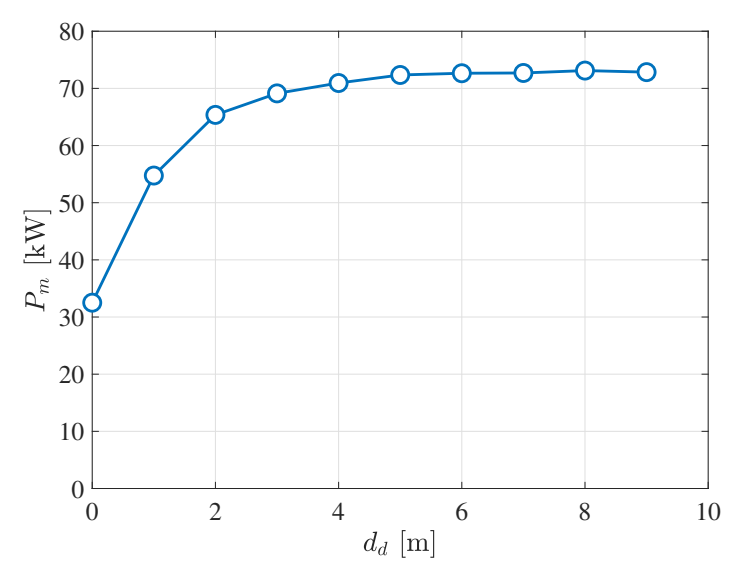

Figure 9. Yearly average output power versus the variation of $d_{d}\left(N=50, R_{r}=2.5 \mathrm{~m}\right.$ and $\left.h_{s}=2 \mathrm{~m}\right)$. 
In the present case a length of the concrete ramp equal to $2 \mathrm{~m}$, corresponding to a yearly average output power of $65.7 \mathrm{~kW}$, is considered the optimal choice.

\subsection{Effects of the Number of Turbines}

The effect of the number of turbines $N$ has been investigated for the optimal configuration of the OBREC system to be installed in the Pantelleria harbour (i.e., $R_{r}=2.5 \mathrm{~m}, h_{s}=2 \mathrm{~m}$ and $d_{d}=2 \mathrm{~m}$ ), and the results obtained concerning the device performances are shown in Figure 10. In particular, Figure 10a shows the yearly average output power $P_{m}$ and Figure $10 \mathrm{~b}$ shows the percentage of time when the reservoir is full, $t_{p}$, as a function of $N$.

(a)

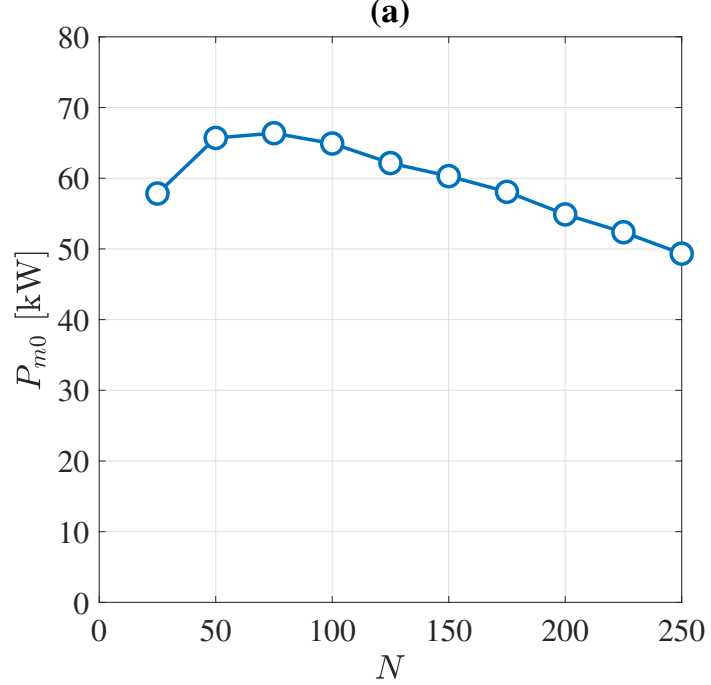

(b)

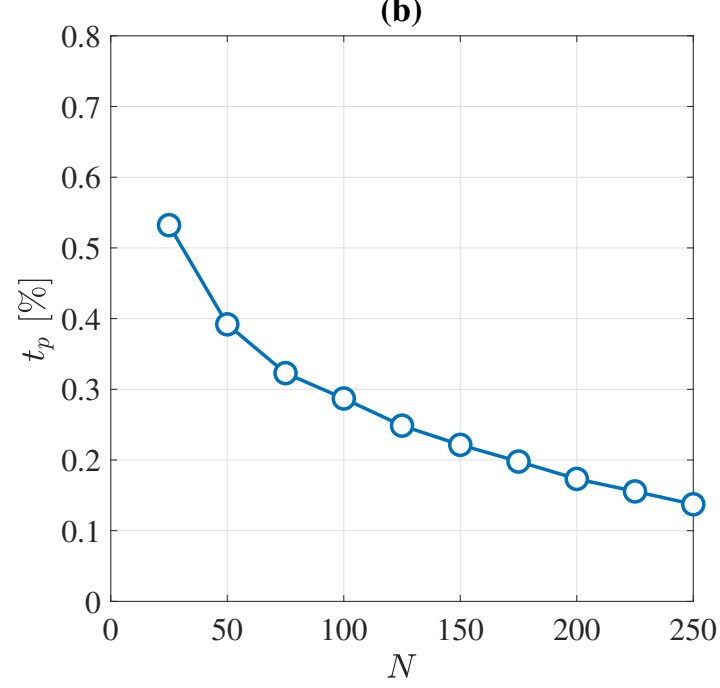

Figure 10. Yearly average output power versus the number of turbines installed (a) and percentage of time when the reservoir is full versus the number of turbines installed $(\mathbf{b})\left(R_{r}=2.5 \mathrm{~m}, h_{s}=2 \mathrm{~m}\right.$ and $\left.d_{d}=2 \mathrm{~m}\right)$.

For smaller values of $N, N<75$, there is an increase in the output power as $N$ increases due to the reduction in the rejected overtopping volumes (Figure 10b). Such a reduction is more significant than the reduction in the average hydraulic head. For $N>75$, the increase of $N$ affects negatively $P_{m}$ because of the monotonous decrease of $t_{p}$ and because the emptying of the reservoir is too fast to allow the formation of sufficiently high hydraulic heads.

The maximum value of the yearly average output power corresponds to $N=75(66.3 \mathrm{~kW})$, but the optimal number of turbines is considered to be $N=50(65.7 \mathrm{~kW})$, since the slight reduction in output power would be compensated by the reduced cost of the turbines.

\subsection{Seasonal and Monthly Output Power}

An analysis of the monthly (Figure 11) average output power of the device operating with the optimal configuration (i.e., $R_{r}=2.5 \mathrm{~m}, h_{s}=2 \mathrm{~m}, d_{d}=2 \mathrm{~m}$ and $N=50$ ) has also been carried out.

Such an irregularity is due to the wave climate itself, which is extremely irregular and it therefore cannot be diminished without encountering very significant losses in the yearly average output power. Indeed, it could be possible to adopt a geometrical configuration more suitable to the exploitation of the low-energy summer waves (i.e., lower values of $R_{r}$ and $h_{s}$ ). However this solution would require the use of a different type of turbines since in the optimal configuration the Kaplan turbines ZD760-LM-80 are already operating close to their lower head of $2 \mathrm{~m}$. Furthermore, with this configuration the device would be very inefficient during the intense sea states, because too low values of $R_{r}$ would cause a great part of the energy to be wasted due to the impossibility of developing high hydraulic heads, and it would also cause the device to be often full with low empting time, thus the rejection of the overtopping volumes due to already reached maximum capacity would be very common. 


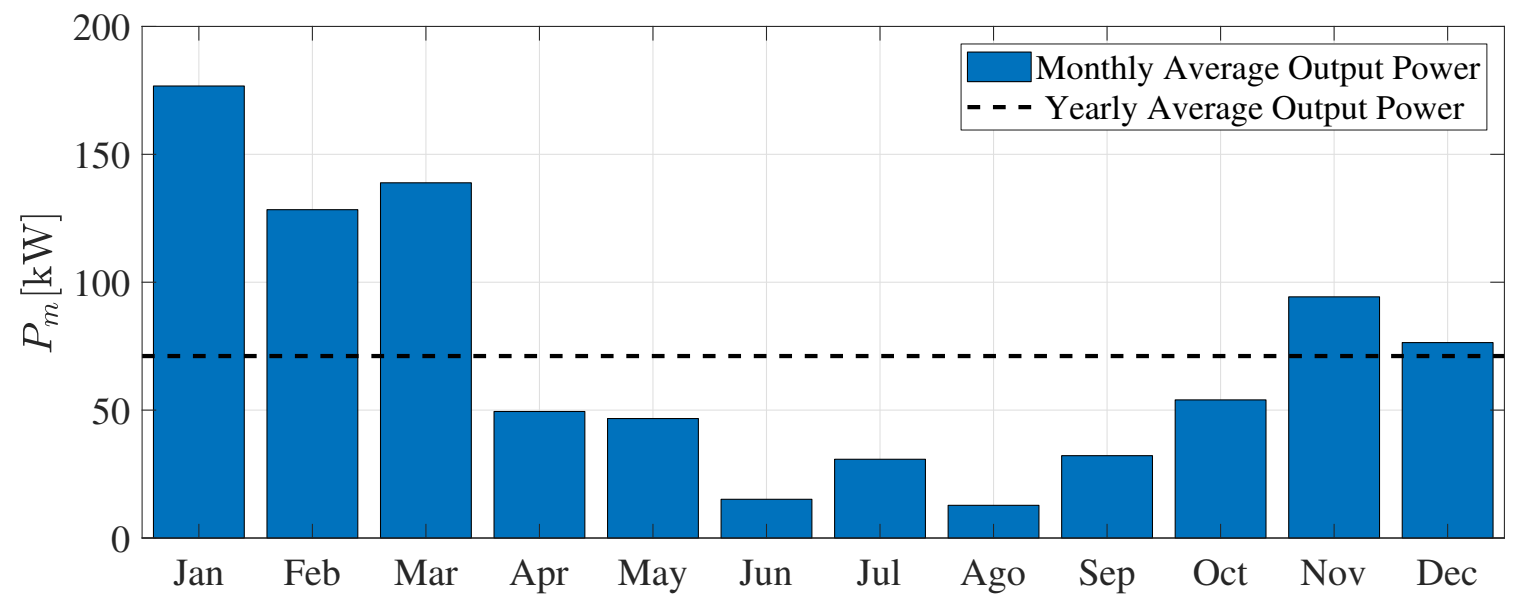

Figure 11. Monthly average output power $\left(R_{r}=2.5 \mathrm{~m}, h_{s}=2 \mathrm{~m}, d_{d}=2 \mathrm{~m}\right.$ and $\left.N=50\right)$.

To confirm the previous statements, the numerical model has been used to test the performance of the device operating with a different type of turbines: the 30type turbines from Electway Elecritc, with an operative head in the range $0.5-2 \mathrm{~m}$.

Figure 12 shows the average output power in the June-July-August trimester and the early average output power as function of $R_{r}$ and $h_{s}$. Figure 13 shows the standard deviation of the monthly average output power $\left(\sigma\left(P_{m}\right)\right)$ versus the variation of $R_{r}$ and $h_{s}$.

(a)

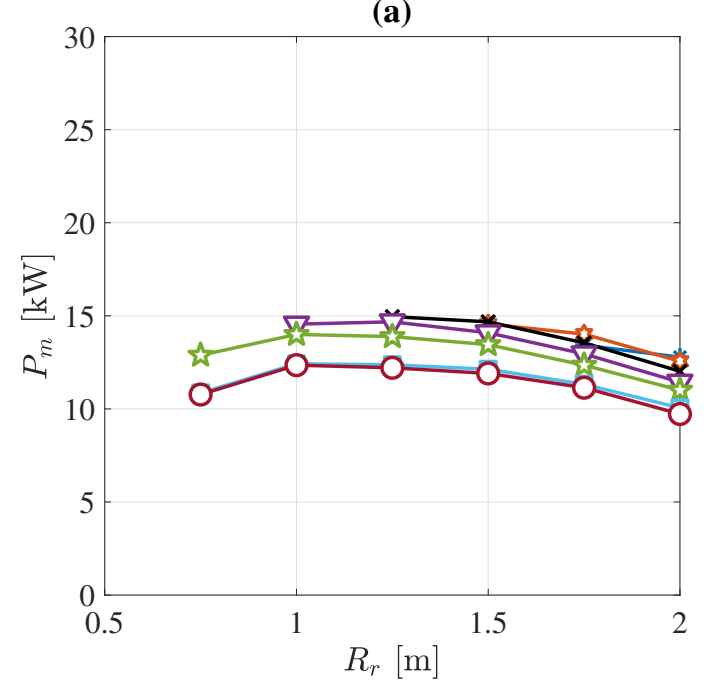

(b)

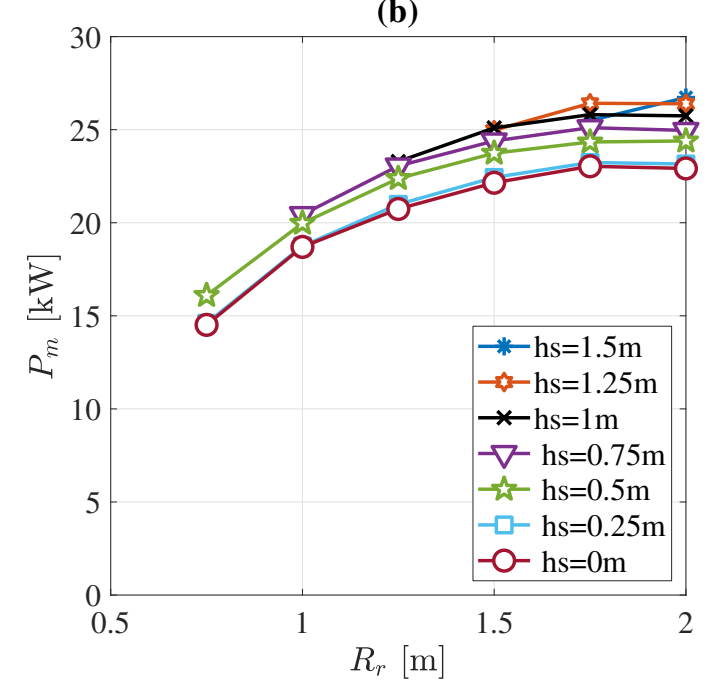

Figure 12. Average output power in the June-July-August trimester versus the variation of $R_{r}$ and $h_{S}$ (a) and yearly average output power versus the variation of $R_{r}$ and $h_{s}(\mathbf{b})\left(N=50, d_{d}=1 \mathrm{~m}\right.$ and the 30type turbines). 


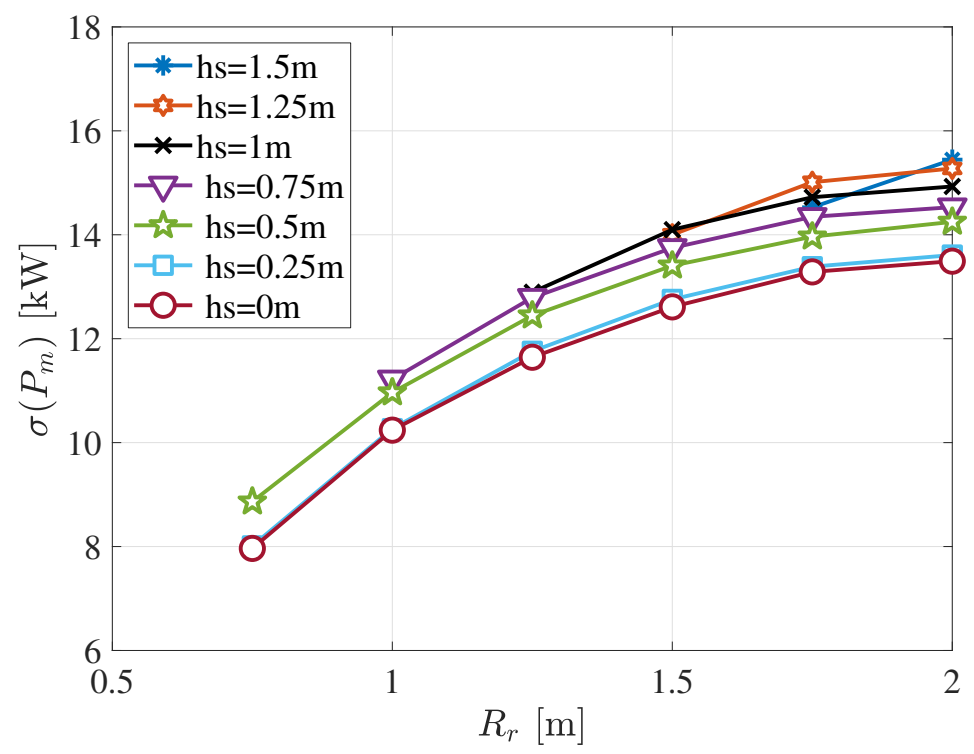

Figure 13. Standard deviation of the monthly average output power versus the variation of $R_{r}$ and $h_{S}$ ( $N=50, d_{d}=1 \mathrm{~m}$ and the 30type turbines).

Figure 12a identifies the optimal configuration regarding the summer performance of the device $\left(R_{R}=1.25 \mathrm{~m}\right.$ and $\left.h_{s}=1 \mathrm{~m}\right)$. However, Figure $12 \mathrm{~b}$ shows that the adoption of a configuration more adequate to operate under the intense sea states works better in terms of yearly average output power. Figure 13 shows that the irregularity of the monthly output power is diminished by the reduction of $R_{r}$.

The optimization of the configuration with $h_{s}=1 \mathrm{~m}$ and $R_{r}=1.25 \mathrm{~m}$, which is the most convenient regarding the summer output power, is achieved by adopting a value of $d_{d}=2 \mathrm{~m}$ and a value of $N=250$. Such a configuration has a value of $P_{m}=61 \mathrm{~kW}$, a value of the summer average output power of $32 \mathrm{~kW}$ and a standard deviation of the monthly average output power of $30.6 \mathrm{~kW}$. The optimal configuration obtained with the ZD760-LM-80 turbines (i.e., $R_{r}=2.5 \mathrm{~m}, h_{s}=2 \mathrm{~m}$, $d_{d}=2 \mathrm{~m}$ and $N=50$ ) had instead a value of $P_{m}=65.7 \mathrm{~kW}$, a summer average output power of $17.2 \mathrm{~kW}$ and a standard deviation of the monthly average output power of $50 \mathrm{~kW}$.

Figure 14 shows the monthly average output power for the optimal configuration with the 30type turbines.

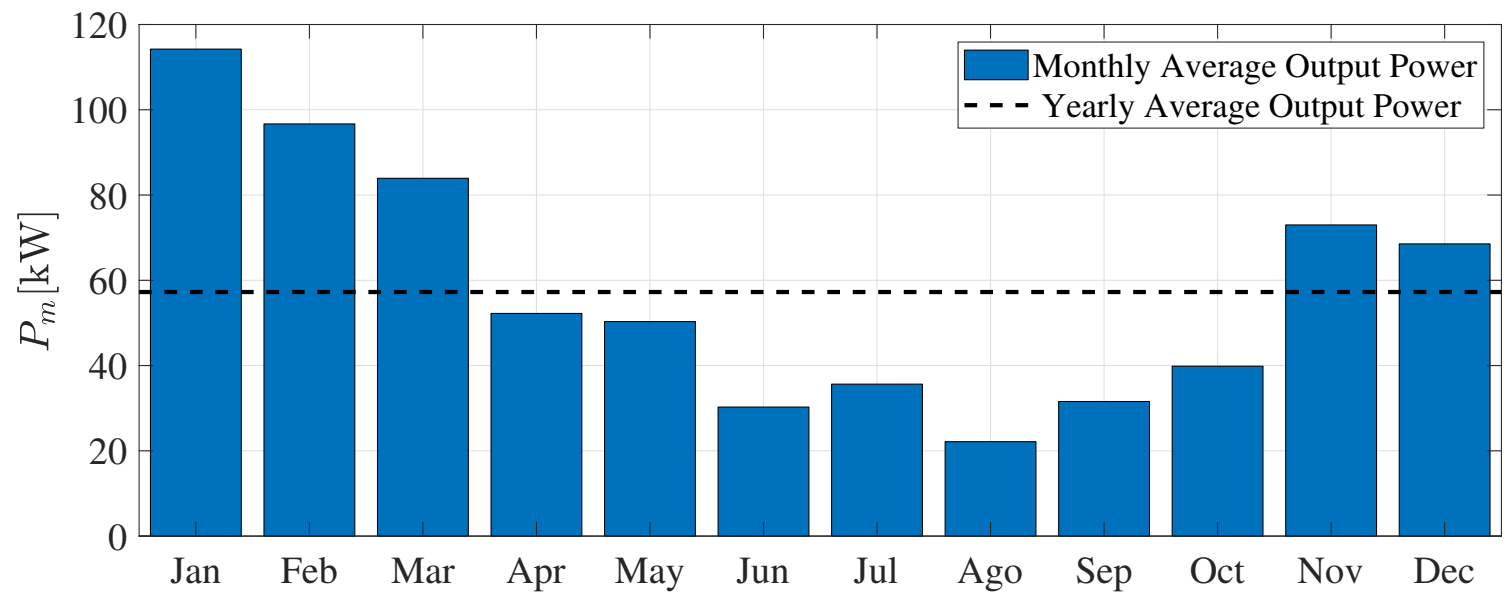

Figure 14. Monthly average output power $\left(R_{r}=1.25 \mathrm{~m}, h_{s}=1 \mathrm{~m}, N=250, d_{d}=2 \mathrm{~m}\right.$ and the 30type turbines). 
The comparison between the two configurations suggests that a more regular monthly average output power can be achieved by using lower hydraulic head turbines, but this would cause a reduction in the yearly average output power (about $7 \%$ ) while still being unable to avoid a relevant seasonal irregularity of the performance of the device.

\subsection{Dynamic Strategy}

The dynamic strategy for managing the output power of the OBREC consists of the adaptation of the number of switched on turbines to the sea state condition, so as to have the device working with the optimal number of turbines during each sea state. In order to apply the dynamic strategy, in a preliminary phase the output power was evaluated for each configuration analysed and for each sea state. Thus, for a given geometrical configuration and a given sea state the optimal number of turbine switched on is evaluated.

Figure 15 shows the yearly average output power versus the variation of $R_{r}$ and $h_{s}$ for a device with 50 turbines installed and with the possibility to turn on a number of turbines between 10 and 50 using blocks of 10 turbines. It can be noticed that the optimal configuration is the one with $R_{r}=2.5 \mathrm{~m}$ and $h_{s}=2 \mathrm{~m}$.

Figure 16 shows the yearly average output power versus the variation of $d_{d}$ for a device with $R_{r}=2.5 \mathrm{~m}, h_{s}=2 \mathrm{~m}$ using the same dynamic strategy.

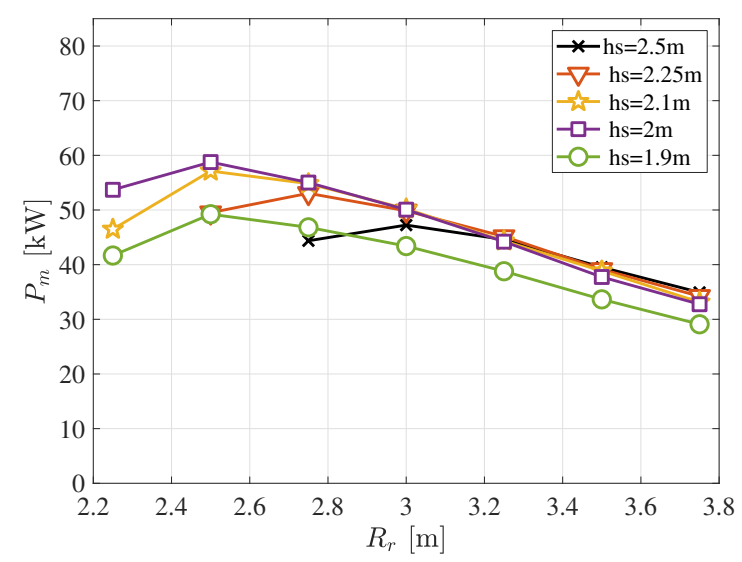

Figure 15. Yearly average output power versus the variation of $R_{r}$ and $h_{s}$ for a device with 50 turbines installed and with the possibility to open a number of turbines between 10 and 50 with steps of 10 $\left(d_{d}=1 \mathrm{~m}\right)$.

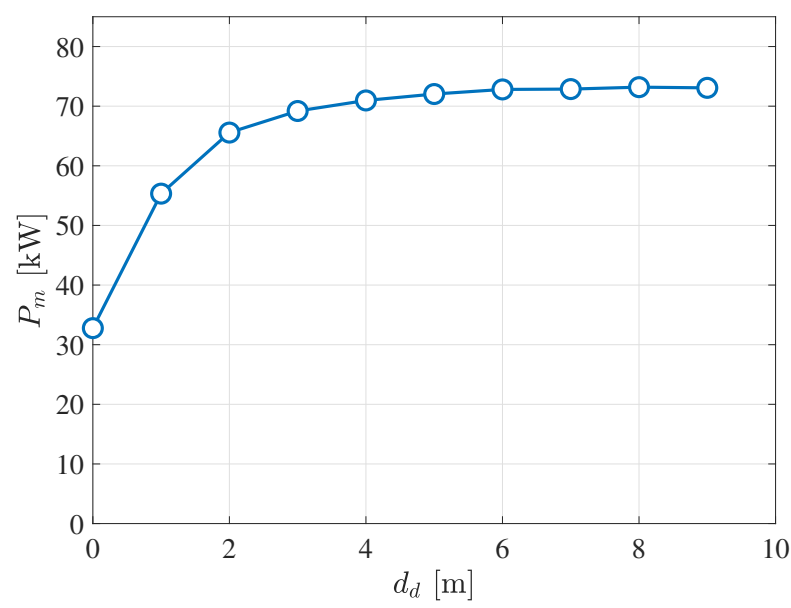

Figure 16. Yearly average output power versus the variation of $d_{d}$ for a device with a number of turned on turbines between 10 and 50 with steps of $10\left(R_{r}=2.5 \mathrm{~m}, h_{s}=2 \mathrm{~m}\right)$. 
The optimal value is once again $d_{d}=2 \mathrm{~m}$.

Finally, Figure 17 shows the comparison between the two different management strategies, that is, the static one with all the installed turbines switched on and the dynamic one, where the number of turbines on depends on the wave conditions.

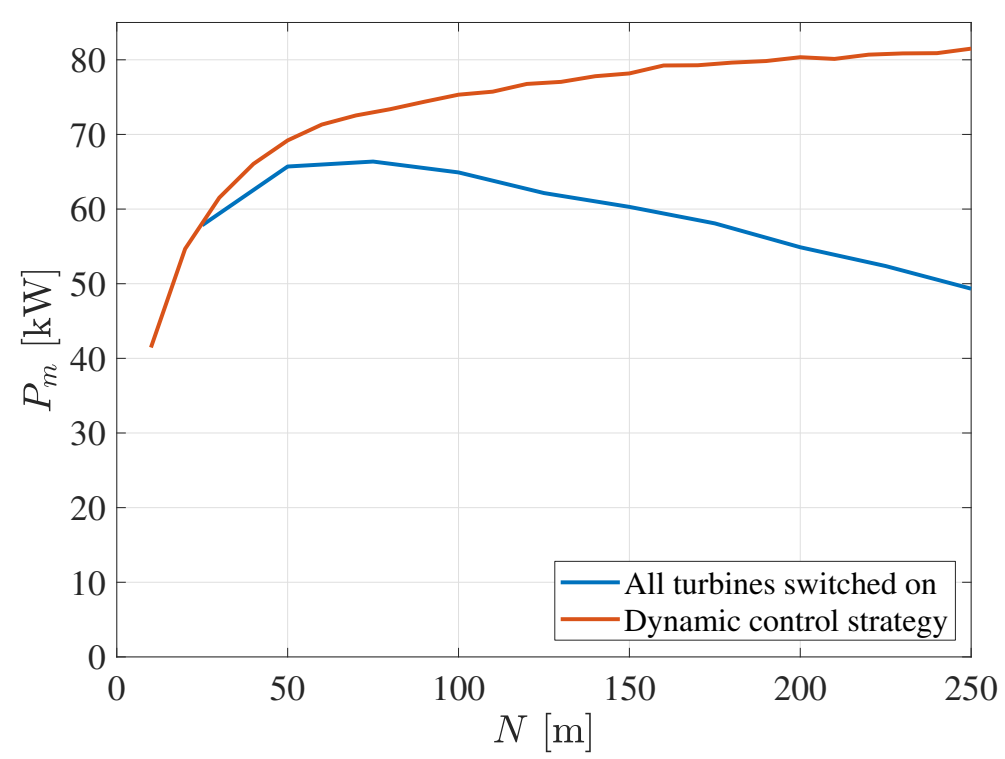

Figure 17. Comparison between the yearly average output power versus the variation of $N$ in the case of the adoption of the static or the dynamic control strategy $\left(R_{r}=2.5 \mathrm{~m}, h_{s}=2 \mathrm{~m}, d_{d}=2 \mathrm{~m}\right.$ and a step of 10 in the choice of the number of open turbines).

The previous graph allows to underline a significant difference introduced by the dynamic strategy on the effect of the number of turbines installed: if all the turbines are always kept switched on, an increase in the number of turbines causes both the device to be more efficient with intense sea states and to be less efficient with weak sea state, so that, when the second effect begins to prevail, the optimal number of turbines to be installed is obtained. The adoption of the second control strategy provides, instead, in the case of an increase of $N$, the possibility to use a more convenient number of turbines (if this exists) without denying the possibility of keeping the previous configuration (if it is the most convenient). This implies that the curve must necessarily be monotonically non-decreasing and must necessarily be greater than or equal to the curve obtained by the adoption of the static control strategy.

The curve associated to the dynamic strategy does not allow to choose over the number of turbines to be made by means of a search for a peak, but it requires to identify the point where a further increment in the number of turbines does not cause an adequate output power. To identify such a point the percentage increase in the yearly average output power $(\Delta)$ versus the variation of $N$ has been evaluated and it is shown in Figure 18.

The minimum percentage increase that justifies the installation of a higher number of turbines is considered here to be about $5 \%$, which corresponds to $N=50$ and to a yearly average output power of $69.2 \mathrm{~kW}$; the optimal number of turbines is therefore the same suggested for the geometrical optimization carried out in Section 5.3. 


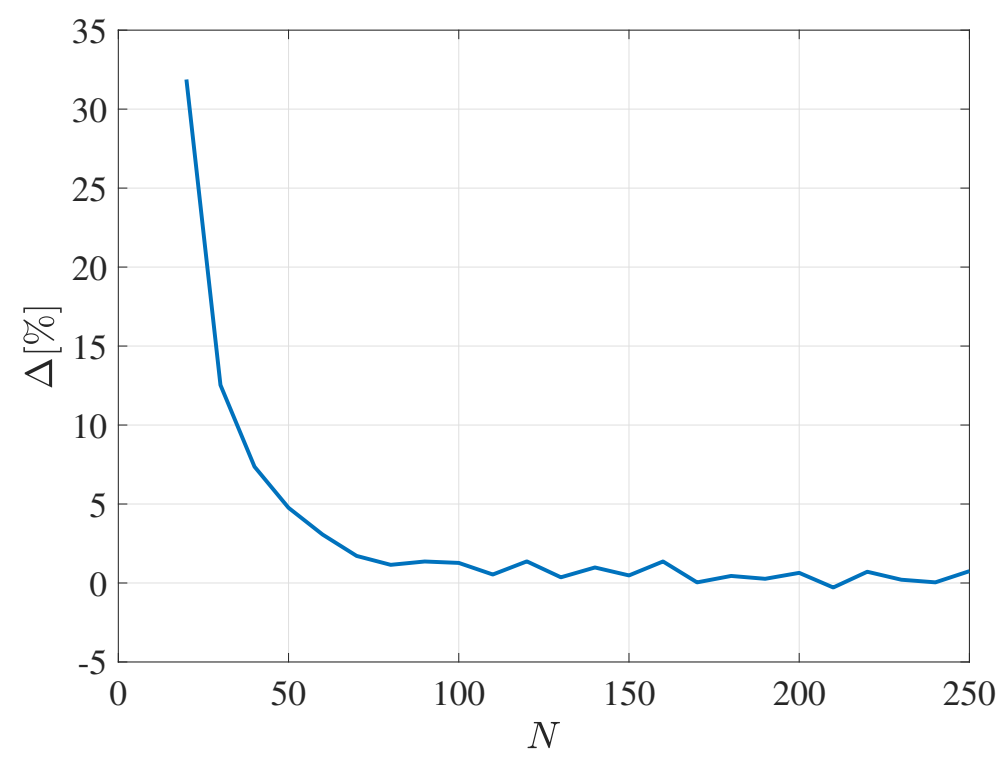

Figure 18. Percentage increase in the yearly average output power versus the variation of $N\left(R_{r}=2.5 \mathrm{~m}\right.$, $h_{s}=2 \mathrm{~m}, d_{d}=2 \mathrm{~m}$ and a step of 10 in the choice of the number of open turbines).

The adoption of the dynamic control strategy leads to an increase in the yearly average output power of only $3.5 \mathrm{~kW}$ (about 5\%) compared to the adoption of the more simple static strategy.

\section{Conclusions}

A numerical model based on the stochastic description of the overtopping phenomenon for the optimization of the performance of the innovative Overtopping BReakwater for Energy Conversion (OBREC) is proposed. As suggest by Contestabile et al. [22], the OBREC gives its best performance (and high economic confidence) in a poor and mild wave climate. This is not necessarily a drawback since the OBREC, like all sea port protection breakwaters, is conventionally built in naturally protected coastal areas. The model was applied at the study site of Pantelleria Island (Sicily, Italy), where the extension of $260 \mathrm{~m}$ of the existing breakwater is expected. The present investigation has the following goals: (i) to identify the main geometrical parameters affecting the device performance; (ii) to propose a methodology to optimize the configuration of a device, considering the case study of the breakwater of Pantelleria Port; (iii) to evaluate the possibility of adopting alternative control strategies of the turbine's functioning to further increase the device's performance.

The main parameters of the device affecting its output power are: the crest free-board of the front reservoir $\left(R_{r}\right)$, the height of the bottom of the reservoir $\left(h_{s}\right)$, the length of the submerged ramp $\left(d_{d}\right)$ and the number of turbines installed. For the present case study, the application of the model allowed to identify the following optimal values of such parameters: $R_{r}=2.5 \mathrm{~m}, h_{\mathrm{s}}=2 \mathrm{~m}, d_{d}=2 \mathrm{~m}$ and $N=50$, with a corresponding yearly average output power of $65.7 \mathrm{~kW}$ and an yearly energy production of about $575 \mathrm{MWh}$. The monthly average output power of the device was found to be extremely irregular, with a peak of $166 \mathrm{~kW}$ in January, a minimum value of less than $10 \mathrm{~kW}$ in August and a standard deviation of $50 \mathrm{~kW}$. To reduce such an irregularity a type of turbine more adequate, in terms of minimum head, to operate during the less energetic summer sea states could be used. This would indeed reduce the standard deviation of the yearly average power production of about $39 \%$ (with a peak in the monthly average output power of $120 \mathrm{~kW}$ during January, and a minimum of $24.3 \mathrm{~kW}$ in August), but would also cause a reduction in the yearly energy production of about $7 \%$, which is not convenient in economic terms.

The dynamic controls strategy, which consists of the dynamic adaptation of the number of active turbines according to the actual sea state condition at the study site, is able to achieve limited increases in the device's power production. 
Pantelleria Island has required, in the year 2011, an approximate production of 44,000 MWh of electricity. The island's municipal authority has defined an objective in the reduction of $\mathrm{CO}_{2}$ emissions of $8372 \mathrm{t}$ per year, of which a part (750 MWh per year) should be satisfied by means of wave energy converters. An OBREC wave energy converter extended along the $260 \mathrm{~m}$ of the new Pantelleria's breakwater could substantially contribute to the achievement of this goal with its yearly energy production of $575 \mathrm{MWh}$ and an approximate reduction in the yearly $\mathrm{CO}_{2}$ emission of $460 \mathrm{t}$, which represents about $5 \%$ of the minimum reduction required by 2020 .

Finally, the results obtained from the present analyses provide a guide for the implementation of an appropriate overall cost optimization approach in future works.

Author Contributions: Conceptualization, L.C. and C.I.; methodology, L.C. and C.I.; formal analysis, F.C. and C.I.; investigation, F.C., C.I. and L.C.; writing-original draft preparation, L.C., C.I., F.C. and R.E.M.; writing-review and editing, L.C., R.E.M. and E.F.; supervision, E.F. All authors have read and agreed to the published version of the manuscript.

Funding: This work has been partly supported by the project "NEWS-Nearshore hazard monitoring and Early Warning System" (code C1-3.2-60) in the framework of the EU programme INTERREG V-A Italia Malta 2014-2020 and by University of Catania funded projects "Interazione onde-correnti nella regione costiera (INOCS)", "Interazione Moto Ondoso-Strutture (IMOS)", and "VAlutazione del Rischio Idraulico in sistemi cOmplessi (VARIO)".

Conflicts of Interest: The authors declare no conflict of interest.

\section{References}

1. IEA-OES. Implementing Agreement on Ocean Energy Systems: Annual Report 2007; Technical Report; International Energy Agency and Ocean Energy Systems (IEA-OES): Paris, France, 2007.

2. Ibarra-Berastegi, G.; Sáenz, J.; Ulazia, A.; Serras, P.; Esnaola, G.; Garcia-Soto, C. Electricity production, capacity factor, and plant efficiency index at the Mutriku wave farm (2014-2016). Ocean Eng. 2018, 147, $20-29$. [CrossRef]

3. Serras, P.; Ibarra-Berastegi, G.; Sáenz, J.; Ulazia, A. Combining random forests and physics-based models to forecast the electricity generated by ocean waves: A case study of the Mutriku wave farm. Ocean Eng. 2019, 189, 106314. [CrossRef]

4. Vicinanza, D.; Contestabile, P.; Nørgaard, J.Q.H.; Andersen, T.L. Innovative rubble mound breakwaters for overtopping wave energy conversion. Coast. Eng. 2014, 88, 154-170. [CrossRef]

5. Iuppa, C.; Contestabile, P.; Cavallaro, L.; Foti, E.; Vicinanza, D. Hydraulic Performance of an Innovative Breakwater for Overtopping Wave Energy Conversion. Sustainability 2016, 8, 1226. [CrossRef]

6. Contestabile, P.; Iuppa, C.; Di Lauro, E.; Cavallaro, L.; Andersen, T.L.; Vicinanza, D. Wave loadings acting on innovative rubble mound breakwater for overtopping wave energy conversion. Coast. Eng. 2017, 122, 60-74. [CrossRef]

7. Di Lauro, E.; Lara, J.L.; Maza, M.; Losada, I.J.; Contestabile, P.; Vicinanza, D. Stability analysis of a non-conventional breakwater for wave energy conversion. Coast. Eng. 2019, 145, 36-52. [CrossRef]

8. Kofoed, J.P.; Frigaard, P.; Friis-Madsen, E.; Sørensen, H.C. Prototype testing of the wave energy converter wave dragon. Renew. Energy 2006, 31, 181-189. [CrossRef]

9. Kofoed, J.P. Wave Overtopping of Marine Structures: Utilization of Wave Energy. Ph.D. Thesis, Aalborg University, Aalborg, Denmark, 2002.

10. Iuppa, C.; Cavallaro, L.; Musumeci, R.E.; Vicinanza, D.; Foti, E. Empirical overtopping volume statistics at an OBREC. Coast. Eng. 2019, 152, doi:10.1016/j.coastaleng.2019.103524. [CrossRef]

11. Van Der Meer, J.W.; Janssen, J.P. Wave Run-Up and Wave Overtopping at Dikes and Revetments; Delft Hydraulics: Delft, The Netherlands, 1994.

12. Franco, L.; De Gerloni, M.; Van der Meer, J. Wave overtopping on vertical and composite breakwaters. In Proceedings of the 24th International Conference on Coastal Engineering, Kobe, Japan, 23-28 October 1994; Volume 1.

13. Victor, L.; Van der Meer, J.; Troch, P. Probability distribution of individual wave overtopping volumes for smooth impermeable steep slopes with low crest freeboards. Coast. Eng. 2012, 64, 87-101. [CrossRef] 
14. van der Meer, J.; Bruce, T. New physical insights and design formulas on wave overtopping at sloping and vertical structures. J. Waterw. Port Coast. Ocean Eng. 2013, 140, 04014025. [CrossRef]

15. EurOtop Manual. EurOtop Manual on Wave Overtopping of Sea Defences and Related Structuresl; EurOtop Manual. 2018. Available online: https:// biblio.ugent.be/publication/8506110 (accessed on 30 October 2020).

16. PAES. Piano D'azione per L'energia Sostenibile; Technical Report; Comune di Pantelleria: Pantelleria, Italy, 2015.

17. Booij, N.; Holthuijsen, L.; Ris, R. 'SWAN' wave model for shallow water. In Proceedings of the 25th International Conference on Coastal Engineering, Orlando, FL, USA, 2-6 September 1996; pp. 668-676.

18. Gorman, R.M.; Neilson, C.G. Modelling shallow water wave generation and transformation in an intertidal estuary. Coast. Eng. 1999, 36, 197-217. [CrossRef]

19. Iuppa, C.; Cavallaro, L.; Vicinanza, D.; Foti, E. Investigation of suitable sites for Wave Energy Converters around Sicily (Italy). Ocean Sci. Discuss. 2015, 12, 315-354. [CrossRef]

20. Liberti, L.; Carillo, A.; Sannino, G. Wave energy resource assessment in the Mediterranean, the Italian perspective. Renew. Energy 2013, 50, 938-949. [CrossRef]

21. De León, S.P.; Orfila, A.; Simarro, G. Wave energy in the Balearic Sea. Evolution from a 29 year spectral wave hindcast. Renew. Energy 2016, 85, 1192-1200. [CrossRef]

22. Contestabile, P.; Di Lauro, E.; Buccino, M.; Vicinanza, D. Economic assessment of Overtopping BReakwater for Energy Conversion (OBREC): A case study in Western Australia. Sustainability 2017, 9, 51. [CrossRef]

Publisher's Note: MDPI stays neutral with regard to jurisdictional claims in published maps and institutional affiliations.

(C) 2020 by the authors. Licensee MDPI, Basel, Switzerland. This article is an open access article distributed under the terms and conditions of the Creative Commons Attribution (CC BY) license (http://creativecommons.org/licenses/by/4.0/). 